\title{
ОСОБЕННОСТИ ФОРМИРОВАНИЯ И РОСТА КЕДРОВЫХ ЛЕСОВ В РАЗЛИЧНЫХ ЛАНДШАФТНЫХ УСЛОВИЯХ ВОСТОЧНОГО САЯНА
}

\section{FEATURES OF THE FORMATION AND GROWTH OF CEDAR FORESTS IN VARIOUS LANDSCAPE CONDITIONS OF THE EASTERN SAYAN}

\section{Briukhanov}

Summary. The article reveals the features of the formation and growth of cedar forests in various landscape conditions of the mountains of southern Siberia. A brief description of the Eastern Sayan is given. The cedar forms prevailing in various landscapes of the Eastern Sayan are analyzed.

Keywords: Eastern Sayan, landscape, cedar forests, Siberian cedar, dark coniferous spruce-cedar-fir forests, larch-cedar forests, needles, fir, phytocenosis, mountain-taiga and high-mountain landscapes.

\author{
Брюханов Игорь Иванович \\ Аспирант, Институт леса им. В.Н. Сукачева СО РАН \\ igor_i_b@mail.ru
}

Аннотация. В статье раскрыты особенности формирования и роста кедровых лесов в различных ландшафтных условиях гор юга Сибири. Дана краткая характеристика Восточного Саяна. Проанализированы формы кедра, преобладающие на различных ландшафтах Восточного Саяна.

Ключевые слова: Восточный Саян, ландшафт, кедровые леса, кедр сибирский, темнохвойные елово-кедрово-пихтовые леса, лиственнично-кедровые леса, хвоя, пихта, фитоценоз, горно-таёжные и высокогорные ландшафты.
B осточный Саян является горной системой, которая территориально расположена в Южной Сибири. Система охватывает юг Красноярского края, западную часть Республики Бурятия, а также Иркутскую область и северо-восточную часть Республики Тыва. Начинается данная система на левом берегу реки Енисей и простирается на 1000 километров, немного не доходя до известного озера Байкал [1].

Рассматривая ландшафты данной горной системы, отметим, что, как правило, это высокогорный и горно-таежный тип ландшафта. Одновременно с этим, в предгорье (до высоты 1000 м.) есть сосновые и светлые лиственные леса, которые сменяются лугово-болотными и лесостепными участками.

Типичные горно-таежные ландшафты, которые занимают больше половины горной системы, развиты на долинах рек и склонах крупных хребтов. Отметим, что для горно-таежного пояса весьма характерно наличие влажного климата и умеренной прохлады. Основная масса представлена таежными, а именно, темнохвойными елово-кедрово-пихтовыми лесами, расположенными на горно-таежных слабоподзолистых светлых глубоко выщелоченных почвах. Данные леса поднимаются на запад и в центральной части могут достигать высоты 1500-1800 метров. Также можно наблюдать более светлые лиственнично-кедровые леса на горно-мерзлых таежных грунтах, а также оподзоленных кислых железистых почвах. Именно они формируют верхнюю границу леса на востоке и юго-востоке, примерно на высоте 2000 метров и более.

Кедр сибирский (Pinus sibirica DuTour) - это вечнозеленое, а также темно-хвойное дерево. Данный вид относят к семейству сосновых (Pinaceae), роду сосновых (Pinus) и подроду Haploxylon (Koehne) Pilg. Ярким признак этой породы - пять игл в одном пучке.

Сибирский кедр достаточно устойчив к гнили, что помогает достигать ему высоты более 40 метров и диаметра ствола 1,5-2 метра. Наибольшая продолжительность жизни данного растения составляет 600-650 лет. Однако как утверждают некоторые исследователи, сибирский кедр вполне может жить 800 лет и более. У молодых деревьев кора является пепельно-серебристой, но с возрастом она темнеет, становится серо-бурой и начинает трескаться. Крона дерева почти всегда густая, а если дерево растет на открытом месте, то она очень раскидистая. Ветвление мутовчатое. Хвоя этого дерева имеет темно-зеленый цвет, его длина 6-17 см., сидит только на укороченных побегах, пучками по 5 игл.

Также стоит акцентировать внимание на том, что сибирский кедр может быть как однодомным, так и двудомным растением. Данное дерево также является анемофильным. Это означает, опыление происходит при участии ветра. Так, мужские колоски данного дерева (микростробилы) собираются у основания побега (рост текущего года), женские шишки (макростробила) 
образуются в генеративном ярусе верхней части кроны на концах ростовых побегов, когда последние заканчивают свой рост, около верхушечной почки. Почки конические, плавно сужающиеся, длиной 6 мм, не смолистые [1].

Крона сибирского кедра включает в себя три яруса. В частности, это верхний ярус, средний и нижний. В насаждении наблюдается только верхний (женский) ярус, на котором образуются только женские шишки. Суммарно он занимает 10-15\% от кроны. Ниже можно наблюдать смешанный ярус, в котором могут образовываться как мужские колоски, так и женские шишки. Средний ярус будет занимать около 50\% всей протяженности коронки. В свою очередь, в нижней части кроны будет располагаться мужской ярус, в котором образуются исключительно мужские колоски с пыльцой. Отметим, что по мере того, как дерево будет расти, а освещенность уменьшаться, ветви женского яруса будут переходить в смешанный ярус, а затем в мужской ярус.

Развитие половых органов и микроспорогенез длится 3 года, как у сосны обыкновенной. В закрытых насаждениях кедр начинает «цвести» с 40-50 лет, в разреженных - с 13-15 лет. Семена созревают на второй год после цветения, а именно, в августе. Стоит отметить, что в условиях чернового подпояса кедр будет цвести в первой половине июня, в то время как в горно-таежном подпоясе - в конце июня и в конце июля в субальпийском поясе. В теории кедр может плодоносить каждый год и каждый год формировать свои репродуктивные органы, однако плодоношение находится в зависимости от того, каковые условия местопроизрастания. Кроме того, плодоношение в данном случае подчиняется климато-метеорологическим факторам, а именно, обеспеченностью теплом и влагой на протяжении сезона.

Основная характерная черта кедровой сосны - это наличие больших и при этом съедобных семян. Данные семена всегда использовались в жизни людей и животных, так как для некоторых видов животных они являются пищей.

Кедр сибирский - это зоохорная порода, то есть расселяющееся с помощью животных. В качестве основного распространителя семян кедра в данном случае является птица кедровка Латынь. Делая запасы на зиму, эта птица прячет их на открытых пространствах, в целях защиты от конкурентов. В данный период, длительность которого составляет порядка двух месяцев, птица способна собрать до 60 кг. орехов. Отметим, что если бы данная птица использовала бы все свои запасы, то их хватило бы на четыре года и более, но не все они поедаются сразу, что обуславливает появление всходов [2, с. 64].
Примечательным является тот факт, что птица-кедровка не выклевывает из шишек пустые семена и делает закладки из 7-12 семян, что позволяет повысить устойчивость всходов в борьбе с травой и прочей растительностью. Также стоит отметить, что если будут иметь место условия, кедровка способна расширить границы распространения кедра, как правило, на 2-4 километра в год. Отсюда следует, что данная птица играет особую роль в процессе естественного возобновления кедра сибирского.

Кроме того, семенами кедра питаются и, тем самым, способствуют его активному распространению, мышевидные грызуны, а также медведи, белки, соболи, бурундуки. Как справедливо отмечал Л.П.Рысин, «это прекрасный пример эволюционно сформировавшихся консорциумных связей с положительным эффектом для вида» [2, с. 64].

Консортные связи - это экологические отношения определенного типа организмов с другими видами, в рамках которых первый вид прямо или косвенно обеспечивает условия для существования второго вида. Примером являются растения и насекомые, которые поселяются на данном растении, например, дереве, и питаются его ресурсами.

Однако «отношения» с животными и птицами у сибирского кедра несколько сложнее, чем у других хвойных пород. Так, как отмечает И.А. Бех: «Кедровка, белка, бурундук, медведь, соболь, ласка, куница, глухарь, рябчик, различные мышевидные грызуны и многие другие представители животного мира постоянно живут в кедровых лесах». В.Ф. Парфенов, отмечая ярко выраженную связь животных с кедровыми лесами, называет это явление «кедровым симбиозом» [7, с. 349].

Сегодня полагают, что именно кедровые леса выступают в качестве места, где концентрируется основное биологическое разнообразие региона. Объясняется это тем, что кедровые леса являются важной стацией для многочисленных представителей таежной фауны и флоры. Более того, кедр занимает почетное место в лесных экосистемах, так как «несмотря на даже небольшую долю участия, как абсолютный долгожитель, он является ядром экосистемы, находясь в основании пирамиды трофических связей, обладая высокими консорциумами и биотическими способностями» [7, с. 349].

С точки зрения экологии кедр сибирский - древесная порода, приспособленная кжизни в горныхусловиях, но также широко распространенная не только на равнинах Восточного Саяна, но и на равнинах Западной Сибири и северной части Урала. Кедр хорошо адаптируется к условиям окружающей среды, при условии наличия 
воздушной влажности, поэтому он не выходит из подроста в лиственничниках Тувы. Предпочитает суглинистые и супесчаные, достаточно влажные, но хорошо дренированные плодородные почвы, заселяя прирусловые валы речек или бугры болот Западной Сибири. Поэтому в пределах своего естественного ареала он встречается на самых разных типах почв. В горах он поднимается до 2 тыс. м и часто образует верхнюю границу леса. На равнине он приурочен к осушаемым и низменным участкам, но растет и в заболоченных поймах рек. Важная биологическая особенность кедра сибирского - зимостойкость, способность расти в суровых климатических условиях и относительная теневыносливость, что приводит к формированию разновозрастных насаждений при отсутствии пожаров и вспышек вредителей.

По теневыносливости кедр сибирский уступает только пихте и ели, что способствует длительной выживаемости подроста кедра под пологом леса. Однако его потребность в свете со временем (к 20 годам) значительно возрастает. Поэтому часто в сомкнутых насаждениях отмирание подроста кедра наблюдается примерно с 16-летнего возраста. При свободном произростании кедр лучше растет, чем под пологом леса. Более требователен к влажности воздуха, чем к почве. Плохо переносит жару и сухой воздух.

Кедр сибирский не переносит мерзлых грунтов, поэтому северная и восточная границы его ареала совпадают с юго-западной границей распространения вечной мерзлоты, где он выбирает дренированные участки (берега рек, южные склоны, скалы).

Экологический оптимум сибирского кедра приурочен к низкогорным районам Восточного Саяна (Назимова, Поликарпов, Семечкин, Поляков, Коновалова и др.). Только здесь продолжительность жизни кедра может достигать 850 лет, есть насаждения выше 40 м. Здесь кедр сибирский - одна из основных лесообразующих пород. Как отмечает В.Ф. Парфенов, «склоны гор на высоте 800-1500 м над уровнем моря - типичные места, где растут кедровые леса, где выпадает достаточное количество осадков» [7, с. 77].

Наиболее продуктивны кедровые леса на пологих северных склонах и поймах рек. Горный рельеф и высотная поясность во многом определяют процентное содержание кедра в составе древесных пород. В Восточном Саяне, например, в черном поясе (до 800 м над уровнем моря) кедр занимает 40\%, пихта - 30\%, береза и осина - 30\%. В горно-таежном подпоясе (800-1500 м над уровнем моря) кедр составляет $85 \%$, а в субальпийском поясе (более 1500 м над уровнем моря) все насаждения в основном представлены чистыми кедровыми лесами.
В то же время Г.В. Крылов (1983 г.) считает, что «в горах юга Сибири потенциальное долголетие и особенности возобновления кедровых лесов во многом определяются высотой ареала». На северных склонах Восточного Саяна в пределах 300-400 м над уровнем моря кедр может жить до 800 лет, в пределах 1000-1500 м - 400 лет, а в пределах 2000-2400 м - всего 40-80 лет [8, с. 128].

Замедленный рост в молодости отличает кедровники от древостоев сосны обыкновенной и сближает их с древостоями пихты и ели. По выходе в первый ярус кедр быстро растет, увеличивает крону, интенсивно плодоносит и быстро приспевает, спеет, поражается гнилями и другими болезнями, фаутируется и распадается. Естественная спелость кедровых древостоев наступает в возрасте 250-320 лет, в производительных условиях местопроизрастания - раньше, а в низкопроизводительных - позже, после чего древостой кедра распадается, превращается в примесь или единичные деревья, уступая преобладание в насаждении более молодому поколению кедра или древостою другой породы.

Качественные признаки, по которым можно судить о жизнеспособности семенного материала и возможности воспроизводства отдельных популяций, имеют сложный характер распределения по высотному профилю. Шишки и семена деревьев горно-таежного и субальпийского поясов не уступают по качеству, а по некоторым параметрам даже превосходят шишки и семена деревьев черной тайги. Ученые объясняют это потеплением, которое активно способствует практической реализации репродуктивной функции у деревьев [2, с. 64].

В черневых кедровых лесах мощное развитие травяного яруса препятствует естественному возобновлению кедра, и на последующих этапах его развития пихта составляет ему конкуренцию. По этим причинам восстановление кедровых лесов в естественных условиях идет медленно и часто приводит к их, иногда необратимой замене, пихтовыми лесами.

В субальпийском поясе, особенно в редколесьях, возобновление кедра также затруднено. Одним из основных ограничивающих факторов для естественного возобновления кедра здесь является значительная высота и густота ярусов трав и кустарников, что создает высокую конкуренцию между видами и препятствует распространению семян кедра кедровками и другими животными. Более того, антропогенный фактор оказывает особую роль для формирования подроста сибирского кедра [2, с. 64].

Высокая интенсивность выпаса приводит к сильному ослаблению подроста и значительной гибели подроста. При этом слабый выпас скота оказывает незначительное 
положительное влияние на ход естественного возобновления кедра за счет уменьшения высоты травостоя и, соответственно, создания более благоприятных условий для внесения семян кедровкой [5].

В литературе отмечается, что в березовых лесах высокая густота отрицательно сказывается на возобновлении кедра только в насаждениях более молодых возрастов; с увеличением возраста древостоя влияние уменьшается. На наш взгляд, это может быть связано с увеличением подкронового пространства у берез и улучшением светового режима подроста, растущего под их пологом.
Не мене важную роль играют сезонные изменения освещенности под кронами лиственных деревьев. В начале вегетации, когда побеги кедра интенсивно развиваются, листовой аппарат березы еще не полностью развит и освещенность выше, чем под кронами пихты.

Таким образом, все вышеизложенное позволяет сделать Вывод о том, что условия для произрастания кедра в березовых и осиновых фитоценозах более благоприятны, чем в хвойных и хвойно-лиственных. Чтобы сократить время восстановления эдификаторной роли кедра, необходимо способствовать его обновлению.

\section{ЛИТЕРАТУРА}

1. Восточный Саян: электронный ресурс.— Режим доступа: http://irkipedia.ru/content/vostochnyy_sayan\#: : text=Восточный\%20Саян\%20—\%20горная\%20система\%2С, направлении\%20почти\%20до\%20берегов\%20Байкала

2. Грибков А.В. Кедровые леса Алтая под угрозой: проблемы охраны и использования, рекомендации по устойчивому лесоуправлению / А.В. Грибков, А.В. Щур, Д.В. Кузменкин; общ. ред. Н.М. Шматков.—М.: Всемирный фонд дикой природы, 2014.—64 с.

3. Данилин Д.М. Разнообразие кедровых лесов в различных биоклиматических секторах Саян / Д.М. Данилина, Д.И. Назимова, М.Е. Коновалова // Итоги и перспективы геоботанических исследований в Сибири. - 2019.- - С. 31-33.

4. Ермаков Н.Б. Ординация лесной растительности гор юга Средней Сибири / Н.Б. Ермаков // Экология. — 2015.— № 5.—C. 339-344.

5. Кедр сибирский: электронный ресурс.—Режим доступа: http://kedr.forest.ru/kedr_sayan.html

6. Крылов Г.В. Кедр / Г.В. Крылов, Н.К. Таланцев, Н.Ф. Козакова; [Введ. Г.В. Крылова].—М.: Лесн. пром-сть, 1983.— 215 с.

7. Парфенов В.Ф. Эксперимент в тайге: Кедроград и устойчивое развитие / В.Ф. Парфенов.— М.: Изд-во НИА-Природа, 2000. — 349 с.

8. Титов Е.В. Гибридизация кедра сибирского / Е.В. Титов.—- Воронеж: ВГЛТА, 2006. - 128 с.

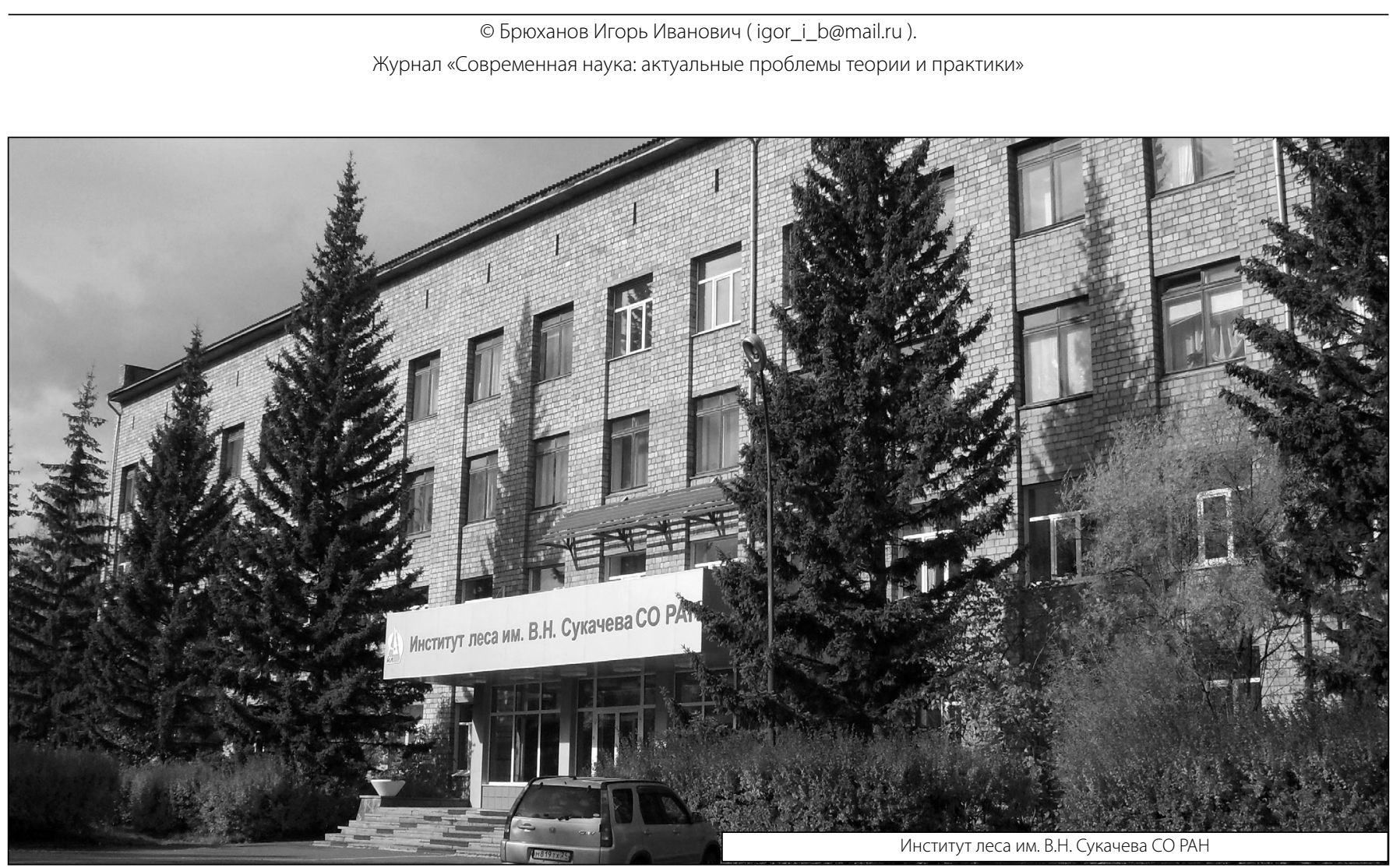

